\title{
Seçilmiş Gelişmekte Olan Ülkelerde Satın Alma Gücü Paritesinin Geçerliliğine İlişkin Ampirik Bir Çalışma
}

DOI: $10.26466 /$ opus.596875

\author{
Yusuf Bozgeyik* - Ayşe Aydın** \\ *Dr. Öğr. Üyesi, Gaziantep Üniversitesi, İktisadi ve İdari Bilimler Fakültesi, Gaziantep/ Türkiye \\ E-Posta: ybozgeyik@gantep.edu.tr \\ ORCID: 0000-0003-2613-2792 \\ **Arş. Gör., Gaziantep Üniversitesi, İktisadi ve İdari Bilimler Fakültesi, Gaziantep/ Türkiye \\ E-Posta: ayseaydin@gantep.edu.tr \\ ORCID: 0000-0002-2152-591X
}

$\ddot{O} z$

Satın alma gücü paritesi teorisi iktisatçılar ve politika yapıcılar tarafından sıklıkla kullanılan uluslararası ekonominin en eski kavramlarından biridir. Satın alma gücü paritesi, küresel boyuttaki fiyat çeşitliliğini elimine etmek ve para birimleri farklllıklarından kaynaklanan satın alma gücünü eşitleyen bir değişim oranıdır. Bu çalışmada da gelişmekte olan ülkelerde SGP' nin geçerli olup olmadığ incelenmiştir. Bu amaç doğrultusunda gelişmekte olan 16 ülkeye ait 1994.01-2019.05 dönemlerini kapsayan aylık reel efektif döviz kuru verileri kullanılarak birim kök testleri yapılmıştır. Birim kök testlerinin uygulanmasında serilerin doğrusallı̆̆l ve yapısal kırılma içerip içermediği önem kazanmaktadır. Furuoka (2017), serilerin doğrusallık ve yapısal kırılmalar altında dört farklı yöntemin mukayesesine olanak veren F-testini önermiştir. Bu çalışmada da literatürde yer alan diğer çalışmalardan farklı olarak dört yöntem uygulanmış ve F-testi sonuçlarına göre her ülke için en iyi model belirlenmiştir. Çalışmanın sonucunda doğrusal olmayan ve yapısal değişimler altında Furuoka (2017) tarafindan geliştirilen Fourier ADF (FADF-SB) testi sonuçları esas alınarak SGP teorisinin Türkiye'nin de aralarında bulunduğu gelişmekte olan 16 ülke için geçerliliğine ulaşılmıştır.

Anahtar Kelimeler: Satın Alma Gücü Paritesi, Fourier ADF testi, Reel Döviz Kuru 


\title{
An Empirical Study on the Validity of Purchasing Power Parity in Selected Developing Countries
}

\begin{abstract}
Purchasing power parity theory is one of the oldest concepts of international economy which is frequently used by economists and policy makers. Purchasing power parity is a rate of change that eliminates global price diversity and equalizes purchasing power due to differences in currencies. In this study, the validity of SGP in developing countries was examined. For this purpose, unit root tests were carried out by using monthly real effective exchange rate data of 16 developing countries covering the periods of 1994.01-2019.05. In the application of unit root tests, the linearity of the series and whether it contains structural fracture gain importance. Furuoka (2017) proposed series F-testing, which allows comparison of four different methods under linearity and structural breaks. In this study, unlike the other studies in the literature, four methods were applied and according to F-test results, the best model was determined for each country. The results of the study were based on the Fourier ADF (FADF-SB) test results developed by Furuoka (2017) under nonlinear and structural changes and the validity of SGP theory is valid for 16 developing countries, including Turkey.
\end{abstract}

Keywords: Purchasing Power Parity, Fourier ADF test, Real Interest Rate 


\section{Giriş}

Satın alma gücü paritesi teorisi iktisatçılar ve politika yapıcılar tarafından sıklıkla kullanılan uluslararası ekonominin en eski kavramlarından biridir. Salamanca Üniversitesi bilim insanlarının 16.yy' da ilk defa kullandığ 1 bu kavram aslında daha uzun bir geçmişe sahiptir. Fakat teorinin ilk ortaya çıkışı Gustav Cassel tarafından ilk olarak 1918 yılında reel döviz kurlarındaki değişimleri hesaplamada kullanılmıştır. Cassel'e göre satın alma gücü paritesi, bir ülkenin parasının satın alma gücünün diğer bir ülkenin parasının satın alma gücüne oranlanmasıdır şeklinde tanımlanmıştır (Yıldırım, Mercan ve Kostakoğlu, 2013).

Satın alma gücü paritesi, küresel boyuttaki fiyat çeşitliliğini elimine etmek ve para birimleri farklılıklarından kaynaklanan satın alma gücünü eşitleyen bir değişim oranıdır. Döviz kuru ve fiyatlar arasındaki ilişki satın alma gücü paritesi üzerinde tartışmalara yol açmıştır. Bu teoriye göre, milli paranın değerinin yurtiçinde ve yurtdışında aynı olması ve ülkeler arasındaki alım gücünün aynı seviyeye getirilmesi hedeflenmektedir. Ülkeler arasındaki satın alma gücünün eşitlenmesi, nominal döviz kurunun göreceli fiyat değişimlerine bağlı kalacağını ve sonuç olarak reel döviz kurunun değişmeyeceğini göstermektedir. $\mathrm{Bu}$ perspektiften bakılacak olursa, satın alma gücü paritesi teorisi döviz kurunun yani farklı para birimlerinin birbiri cinsinden fiyatının belirlenmesinde kullanılmaktadir.

Satın alma gücü paritesinin açılarken üç kavram üzerinde durmakta fayda vardır: Tek Fiyat Kanunu, Mutlak Satın Alma Gücü Paritesi, Nispi Satın Alma Gücü Paritesi. Öncelikli olarak teoriyi analiz edebilmek için tek fiyat kanununun iyi bilinmesi gerekmektedir. SGP'nin uluslar arası piyasalara entegrasyonu tek fiyat kanununun uygulanmasiyla gerçekleşmektedir. Tam rekabet piyasası koşulları altında, ticari engellerin olmadığı, taşıma ve işlem maliyetlerinin bulunmadığı, homojen bir malın farklı piyasalarda aynı fiyata sahip olması gerektiği düşüncesi tek fiyat kanununun temel dayanağıdır. Literatürde Mutlak SGP'yi tanımlarken Tek Fiyat Kanununun genel fiyatlar seviyesine geniş̧letilmiş halidir denilmektedir. Döviz kurlarındaki dengeyi sağlayan mutlak SGP, ülkeler arasındaki fiyat seviyelerinin oranının döviz kurlarını etkilediğini, 
nispi SGP ise döviz kurlarındaki değişimlerin enflasyon oranındaki farklılıklardan kaynaklandığını belirtmektedir.

Tüm bu bilgiler çerçevesinde, serbest ticaret koşullarında, işlem maliyetlerinin minimize edilerek, benzer nitelikteki malların fiyatlarının ölçümünde tek bir döviz kurunun kullanılması fiyatlarının aynı olduğunu ve bu sebeple ülkelerarasındaki farklı fiyatların döviz kuru üzerinde önemli rol oynadığını söyleyen teori satın alma gücü paritesi teorisi olarak bilinmektedir.

SGP teorisinin geçerliliğini test ederken, reel döviz kurlarının durağanlığı araştırılmaktadır. Reel döviz kurlarındaki değişmeler, SGP' den sapmaların olduğunun göstergesidir. $\mathrm{Bu}$ serilerde gözlenen durağan dışılık, SGP teorisinin geçerli olmadığını göstermektedir. Örneğin, reel döviz kuru uluslar arası rekabetçiliğin bir göstergesi olarak hizmet ettiği için reel bir değer kaybı ile rekabetçilikte artışı beraberinde getirecek ve istihdam değer kaybeden ülkeye doğru kayacaktır. (Bahmani-Oskooee ve Rhee, 1992).

Çalışmada Türkiye'nin de aralarında bulunduğu gelişmekte olan 16 ülke için 1994.01-2019.05 yılları arasında SGP hipotezinin geçerliliğinin birim kök testleriyle sınanması amaçlanmaktadır. Çalışmanın ilk bölümünde, SGP teorisinden genel hatlarıyla bahsedilmiştir. Literatür taraması kısmında SGP geçerliliğini analiz eden çalışmalara yer verilmiştir. Üçüncü bölümde ise çalışmada kullanılacak olan veri setinden bahsedilerek metodoloji tanıtılmıştır. Son bölümde ise SGP hipotezinin geçerliliği analiz edilerek yapılan ekonometrik uygulama sonuçları değerlendirilecektir.

\section{Literatür Taraması}

Literatüre bakıldığında SGP geçerliliğini birim kök testleri ve eş bütünleşme testleri ile analiz eden çalışmalara rastlanmaktadır. Çalışmamızda literatürden farklı olarak 1994-2019 yılları arasında aylık veriler kullanılarak aralarında Türkiye'nin de bulunduğu gelişmekte olan 16 ülkenin SGP hipotezinin geçerliliği yapılan birim kök testleriyle analiz edilmiştir. Çalışmanın bu kısmında daha önce yapılan SGP hipotezinin geçerliliğini gösteren teorik ve ampirik çalışmalara yer verilmiştir. 
Türkiye için döviz kurlarının Dolar ve Mark cinsinden SGP geçerliliği, Gürbüz ve Hasgür (1997) tarafından test edilmiştir çalışmada 1970- 1994 yılları arasında çeyrek dönemlik veriler kullanılmıştır. Yapılan eşbütünleşme testleri yardımıyla Dolar ve Mark döviz kuru SGP'yi desteklemektedir. Erlat (2003) 1984-2000 dönemi için yaptığ çalışmada kırılmalı birim kök testleri ve AFRIMA modelini kullanmıştır. Çalışmanın sonucunda Türkiye için SGP hipotezinin geçerliliğine ulaşılmıştır. Alba ve Park (2005) yaptıkları çalışmada 1973:01-2004:10 dönemi için Türkiye' de SGP geçerliliğini doğrusal olmayan birim kök testleri kullanarak incelemişlerdir. Testler sonucunda bir bölümde SGP'nin geçerliliği görülürken iken diğer bölümde SGP'nin geçerli olmadığı görülmüştür.

Benassy ve diğ. (2005) panel birim kök ve panel eş-bütünleşme testlerini kullanarak G20 ülkeleri için 1980-2001 dönemleri arasında yıllık veriler ile SGP hipotezinin geçerliliğini sınamışlardır. Sonuç olarak döviz kurlarında meydana gelen önemli sapmalar hipotezin geçerli olmadığını göstermiştir. Aslan ve Kanbur (2007) Türkiye için 1982:01-2001:01 ve 2001:01-2005:12 dönemleri için hipotezin geçerliliğini eşbütünleşme analizi yaparak test etmişlerdir. Analiz sonucunda SGP'nin geçerli olmadığ görülmüştür. Çağlayan ve Şak (2009) aralarında Türkiye'nin de bulunduğu OECD ülkeleri için yapılan çalışmada SGP hipotezini 1996:012006:04 dönemleri için gelir düzeyi yüksek 20 ülke ve gelir düzeyi düşük 6 ülke için analiz etmişlerdir. OECD ülkelerinin tamamında ve iki farklı gelir grubunda SGP'nin geçerli olmadığı görülmüştür.

Guloglu vd. (2011) reel döviz kurlarının durağanlığını 1991-2008 dönemi içinde Türkiye ve 18 ülke için panel KPSS testi kullanarak sınamışlardır ve sonuç olarak SGP'nin geçerliliği gözlemlenmiştir. Yıldırım vd. (2012) klasik ve kırılmalı birim kök testleriyle 1990:01-2009:12 dönemi arasında Türkiye için üretici ve tüketici fiyat endeksi kullanılarak yapılan çalışmada, SGP'nin geçerliliği tüketici fiyat endeksi göz önüne alındığında, SGP'nin geçerli olmadığı ise üretici fiyat endeksi göz önüne alındığında görülmüştür. Cuestas ve Regis (2013) 1972:01-2010:01 döneminde OECD ülkeleri için SGP geçerliliğini incelemişlerdir. İnceleme sonuçlarına göre doğrusal ve doğrusal olmayan birim kök testleri 11 ülkede SGP'nin geçerliliğini, Türkiye'de ise geçersiz olduğunu göstermiştir. Şener, Yılancı ve Canpolat (2015) iki farklı birim kök testi 
(klasik- çoklu kırılmalı birim kök testleri) kullanarak 1980:01-2012:12 dönemi için Türkiye'de SGP geçerliliğini test etmişlerdir. Çalışmanın sonucunda Türkiye'de sınırlı SGP ile kırılmalı-trendli-sınırlı SGP'nin geçerli olduğu bulgularına ulaşılmıştır.

Tıraşoğlu (2014) 18 OECD ülkesinde 1993:Q1- 2011:Q1 dönemi için tek ve iki kırılmalı birim kök testleriyle yapılan çalışmada, tek kırılmalı birim kök testi sonucuna göre aralarında Türkiye'nin de bulunduğu 10 ülkede SGP'nin geçerliliği görülürken, iki kırılmalı birim kök testi sonucunda yine Türkiye'nin de dâhil olduğu 13 ülkede SGP'nin geçerliliği gözlemlenmiştir. Çeviş ve Ceylan (2015) Kırılgan beşli diye adlandırılan ülkeler için 2003:01-2013:08 döneminde eşbütünleşme testini kullanmışlardır. Çalışma sonucuna göre, Hindistan, Brezilya, Güney Afrika ve Türkiye için SGP hipotezinin geçerli olduğu görülmüştür. Alper (2015), 2001: 01-2014: 09 dönemi için BRICS (Brezilya, Rusya, Hindistan, Çin ve Güney Afrika) ülkelerinin SGP geçerliliğini KSS birim kök testi ile sınamıştır. KSS testinde, SGP hiçbir ülke için geçerli değildir, KSS birim kök testi yuvarlandığında ise SGP kısa zaman aralıklarında geçerlidir. Destek ve Okumuş (2016), SGP hipotezinin geçerliliğini 27 OECD ülkesi için dört farklı birim kök testi kullanarak (ADF birim kök testi, KSS birim kök testi, Fourier ADF ve Fourier KSS) analiz etmişlerdir. Yapılan analiz sonucunda 14 OECD ülkesinde SGP hipotezinin geçerli olduğuna ulaşılmıştır. Sağlam ve Sönmez (2017), BRICT (Brezilya, Rusya, Hindistan, Çin ve Türkiye) ülkeleri için yapılan yapısal kırılma testleriyle SGP'nin geçerliliğini araştırmıştır. Elde edilen sonuçlara göre, BRICT ülkelerinde SGP teorisinin geçerli olmadığ 1 görülmüştür. Çil ve Tiraşoğlu (2018) yaptıkları çalışmada Kırılgan Beşli ülkeri (Brezilya, Endonezya, Güney Afrika, Hindistan ve Türkiye) için 1990:Q1 - 2016: Q2 dönemleri arasında SGP hipotezinin geçerliliğini ADF ve Bayesian birim kök testlerini kullanarak analiz etmişlerdir ve sonuç olarak sadece Hindistan için SGP hipotezinin geçerliliğine ulaşmışlardır. 
Tablo 1- Literatürde Yapılan Bazı Çalışmalar

\begin{tabular}{|c|c|c|c|}
\hline Çalışma & Örneklem & Dönem & Sonuç \\
\hline $\begin{array}{l}\text { Gürbüz ve } \\
\text { Hasgür (1997) }\end{array}$ & Türkiye & 1970- 1994 & SGP geçerli. \\
\hline Erlat (2003) & Türkiye & 1984-2000 & SGP geçerli. \\
\hline $\begin{array}{l}\text { Alba ve Park } \\
(2005)\end{array}$ & Türkiye & $1973-2004$ & $\begin{array}{l}\text { Bir bölümde SGP geçerli diğer } \\
\text { bölümde geçersiz. }\end{array}$ \\
\hline $\begin{array}{l}\text { Benassy } \\
\text { vd.(2005) } \\
\end{array}$ & $\begin{array}{l}\text { G20 } \\
\text { ülkeleri }\end{array}$ & $1980-2001$ & SGP geçersiz. \\
\hline $\begin{array}{l}\text { Aslan ve } \\
\text { Kanbur (2007) }\end{array}$ & Türkiye & $\begin{array}{l}\text { 1982:01-2001:01 } \\
\text { ve 2001:01- } \\
\text { 2005:12 }\end{array}$ & SGP geçersiz. \\
\hline $\begin{array}{l}\text { Çağlayan ve } \\
\text { Şak (2009) }\end{array}$ & $\begin{array}{l}\text { OECD } \\
\text { ülkeleri }\end{array}$ & 1996:01-2006:04 & SGP geçersiz. \\
\hline $\begin{array}{l}\text { Guloglu vd. } \\
(2011)\end{array}$ & $\begin{array}{l}\text { Türkiye } \\
\text { ve } 18 \text { ülke }\end{array}$ & 1991-2008 & SGP geçerli. \\
\hline $\begin{array}{l}\text { Yildırım vd. } \\
(2012)\end{array}$ & Türkiye & 1990:01-2009:12 & $\begin{array}{l}\text { Tüfe baz alındığında SGP geçerli, } \\
\text { Üfe baz alındığında SGP geçer- } \\
\text { siz. }\end{array}$ \\
\hline $\begin{array}{l}\text { Cuestas ve } \\
\text { Regis (2013) } \\
\end{array}$ & $\begin{array}{l}\text { OECD } \\
\text { ülkeleri }\end{array}$ & 1972:01-2010:01 & $\begin{array}{l}11 \text { ülkede SGP geçerli, Türkiye'de } \\
\text { ise geçersiz }\end{array}$ \\
\hline $\begin{array}{l}\text { Şener, Yilancı } \\
\text { ve Canpolat } \\
(2015) \\
\end{array}$ & Türkiye & 1980:01-2012:12 & SGP geçerli. \\
\hline Tiraşoğlu (2014) & $\begin{array}{l}18 \text { OECD } \\
\text { ülkesi }\end{array}$ & $\begin{array}{l}\text { 1993:Q1- } \\
\text { 2011:Q1 }\end{array}$ & SGP geçerli. \\
\hline $\begin{array}{l}\text { Çeviş ve Ceylan } \\
\text { (2015) }\end{array}$ & $\begin{array}{l}\text { Kurılgan } \\
\text { beşli } \\
\text { ülkeleri }\end{array}$ & 2003:01-2013:08 & SGP geçerli. \\
\hline Alper (2015) & $\begin{array}{l}\text { BRICS } \\
\text { ülkeleri }\end{array}$ & 2001: 01-2014: 09 & SGP geçersiz. \\
\hline $\begin{array}{l}\text { Destek ve } \\
\text { Okumuş (2016) }\end{array}$ & $\begin{array}{l}27 \text { OECD } \\
\text { ülkesi }\end{array}$ & $1990-2015$ & $\begin{array}{l}14 \text { OECD ülkesinde SGP hipotezi } \\
\text { geçerli }\end{array}$ \\
\hline $\begin{array}{l}\text { Sağlam ve } \\
\text { Sönmez (2017) }\end{array}$ & $\begin{array}{l}\text { BRICT } \\
\text { ülkeleri }\end{array}$ & 1994-2015 & SGP geçersiz. \\
\hline $\begin{array}{l}\text { Çil ve Tiraşoğlu } \\
\text { (2018) }\end{array}$ & $\begin{array}{l}\text { Kirılgan } \\
\text { beşli } \\
\text { ülkeleri }\end{array}$ & $\begin{array}{l}\text { 1990:Q1 - 2016: } \\
\text { Q2 }\end{array}$ & $\begin{array}{l}\text { Hindistan için SGP hipotezi } \\
\text { geçerli }\end{array}$ \\
\hline
\end{tabular}




\section{Çalışmada Kullanılan Veri Seti}

Çalışmada gelişmekte olan ülkelerinin 1994.01-2019.05 tarihleri arasındaki aylık reel efektif döviz kuru verileri kullanılmıştır. Reel döviz kuru formülü yardımıyla hesaplanmıştır. Formülde yer alan , reel döviz kurunu, nominal döviz kurunu, yurtdışı fiyat düzeyini ve yurtiçi fiyat düzeyini temsil etmektedir. Örneklem seçiminde Morgan Stanley Capital International (MSCI) tarafından oluşturulan gelişmekte olan ülke sınıflandırılması kullanılmış ve analiz dönemi boyunca verisi süreklilik göstermeyen ülkeler elenmiştir. Türkiye'ye ait veriler TMB-EVDS, diğer gelişmekte olan ülkelere ait veriler ise IMF (International Monetary Fund)'ye ait IFS (International Financial Statistics) veri tabanından elde edilmiştir. Çalışmaya dahil edilen 16 ülke ve kısaltmaları Tablo 2'de gösterilmiştir.

Tablo 2. Çalışmaya Dahil Edilen Ülkeler ve Kısaltmaları

\begin{tabular}{llllll}
\hline \hline Ülke Adı & Kisaltma & Ülke Adı & Kisaltma & Ülke Adı & Kisaltma \\
\hline \hline Brezilya & BRA & Macaristan & HUN & Polonya & PLN \\
Şili & CHL & Malezya & MLY & Rusya & RUS \\
Çin & CHN & Meksika & MEX & Suudi Arabistan & SAU \\
Kolombiya & CLM & Pakistan & PAK & Güney Afrika & SOU \\
Çekya & CHZ & Filipinler & PHL & Türkiye & TUR \\
Yunanistan & GRC & & & & \\
\hline \hline
\end{tabular}

\section{Çalışmada Kullanılan Yöntem}

Satın alma gücü paritesini test eden çalışmalar incelendiğinde genellikle farklı bulguların elde edildiği ve henüz bir fikir birliği sağlanamadığ görülmektedir. Çalışmalarda kullanılan veri setinin kapsadığı dönem ve özellikle kullanılan ekonometrik yöntemlerin farklı olması bu durumun oluşmasına neden olmaktadır. SGP'nin varlığının birim kök testleri ile incelendiği çalışmalarda genellikle ADF (Dickey ve Fuller, 1979) birim kök testinin kullanıldığı görülmektedir. Serilerin doğrusal formda olmaması durumunda Enders ve Lee (2012) tarafından geliştirilen Fourier ADF (FADF) testi, yapısal değişimlerin incelendiği durumlarda ise Zivot ve 
Andrews (1992) ve Perron ve Vogelsang (1992) tarafından geliştirilen yapısal kırılmalı ADF (ADF-SB) testi kullanılabilmektedir. Furuoka (2017), serilerin doğrusal formda olmaması ve yapısal değişim içermesi durumunda yapısal kırılmaya izin veren Fourier ADF (FADF-SB) testini geliştirmiştir. Ayrıca, dört alternatif test içerisinden en iyi modeli belirlemeye yönelik 5 farklı F-testi önermiştir. ADF testini Model A, FADF testini Model B, ADF-SB testini Model C ve FADF-SB testini Model D olarak özetlemiştir. Birinci F-testi Model A'ya karşı Model B'yi, ikinci F-testi Model A'ya karşı Model C'yi, üçüncü F-testi Model A'ya karşı Model D'yi, dördüncü F-testi Model B'ye karşı Model D'yi, beşinci F-testi ise Model $C^{\prime}$ ye karşı Model D'yi test etmektedir. Eğer seri doğrusal formda ve yapısal kırılma içermiyorsa Model A, doğrusal olmayan formda ve yapısal kırılma içermiyorsa Model B, doğrusal formda ve yapısal kırılma içeriyorsa Model C, doğrusal olmayan formda ve yapısal kırılma içeriyorsa Model D tercih edilecektir. Söz konusu F-testleri sayesinde veri setine en uygun model belirlenecek ve o modelin çıtıları esas alınacaktır.

Her dört modelde de temel hipotez şu şekilde kurulmaktadır:

$$
y_{t}=\mu+y_{t-1}+\varepsilon_{t}
$$

$y_{t}$, reel döviz kurunu, $\mu$ deterministik terimi ve $\varepsilon_{t}$ hata terimini temsil etmektedir. Alternatif hipotezler de şu şekilde kurulmaktadır:

Model A: $y_{t}=\mu+\beta_{t}+\varepsilon_{t}$

Model B: $y_{t}=\mu+\beta_{t}+\gamma_{1} \sin \left(\frac{2 \pi k t}{T}\right)+\gamma_{2} \cos \left(\frac{2 \pi k t}{T}\right)+\varepsilon_{t}$

Model C: $y_{t}=\mu+\beta_{t}+\delta D U_{t}+\theta D\left(T_{B}\right)_{t}+\varepsilon_{t}$

Model D:

$$
y_{t}=\mu+\beta_{t}+\gamma_{1} \sin \left(\frac{2 \pi k t}{T}\right)+\gamma_{2} \cos \left(\frac{2 \pi k t}{T}\right)+\delta D U_{t}+\theta D\left(T_{B}\right)_{t}+\varepsilon_{t}
$$

Denklemlerde yer alan $\beta$ terimi trend için eğim parametresini, $k$ terimi Fourier yaklaşımı için frekans sıklı̆̆ını, $\gamma$ terimi trigonometrik terimler için eğim parametresini, $t$ terimi deterministik trendi, $T$ terimi gözlem 
sayısını, $=3.1416$ ve $\delta$ terimi ise yapısal kırılma kuklaları için eğim parametresini göstermektedir. Görüldüğü üzere Model A denkleminde sadece deterministik terim ve deterministik trend yer almaktadır. Model B' de doğrusal olmayan trigonometrik terimler eklenmiştir. Model $C^{\prime}$ de tek yapısal kırılma için kukla değişken eklemiştir. Nihayetinde Model D denkleminde tüm dört deterministik katsayı eklenmiştir (Furuoka, 2017). Söz konusu dört denklem şu şekilde hesaplanmıştır:

Model A:

$$
\Delta y_{t}=\mu+\beta_{t}+\rho y_{t-1}+\sum_{i=1}^{p} c_{i} \Delta y_{t-i}+\varepsilon_{t}
$$

Model B:

$\Delta y_{t}=\mu+\beta_{t}+\gamma_{1} \sin \left(\frac{2 \pi k t}{T}\right)+\gamma_{2} \cos \left(\frac{2 \pi k t}{T}\right)+\rho y_{t-1}+\sum_{i=1}^{p} c_{i} \Delta y_{y-i}+\varepsilon_{t}$

Model C:

$$
\Delta y_{t}=\mu+\beta_{t}+\delta D U_{t}+\theta D\left(T_{B}\right)_{t}+\rho y_{t-1}+\sum_{i=1}^{p} c_{i} \Delta y_{t-i}+\varepsilon_{t}
$$

Model D:

$\Delta y_{t}=\mu+\beta_{t}+\gamma_{1} \sin \left(\frac{2 \pi k t}{T}\right)+\gamma_{2} \cos \left(\frac{2 \pi k t}{T}\right)+\delta D U_{t}+\theta D\left(T_{B}\right)_{t}+\rho y_{t-1}+\sum_{i=1}^{p} c_{i} \Delta y_{t-i}+\varepsilon_{t}$

$\rho$ terimi gecikmeli bağımlı değişken için eğim parametresini, $c$ terimi gecikmeli bağımlı değişkeninin birinci farkının eğim parametresini, $p$ terimi ise gecikme uzunluğunu temsil etmektedir (Gemici ve Polat, 2018).

\section{Bulgular}

Çalışmada gelişmekte olan ülkelere ait reel döviz kuru verileri her dört model için de test edilmiş ve modeller arasındaki seçim için F-test istatistikleri hesaplanmıştır. Analiz çıktıları Tablo 3, Tablo 4, Tablo 5 ve Tablo 6 'da gösterilmiştir. Ayrıca gelişmekte olan ülkelerin reel döviz kuru serilerine ait zamanyolu grafiği ve her seriye ait Model D'den elde edilen trend çizgisi Şekil 1 ve Şekil 2' de grafik halinde verilmiştir. 
Tablo 3'te Brezilya, Şili, Çin ve Kolombiya'ya ait bulgular yer almaktadır. Brezilya ve Kolombiya için F-testi sonuçları incelendiğinde Model B ve C'nin Model A'ya göre, Model D'nin de Model A, B ve C'ye göre üstün olduğu görülmektedir. Dolayısıyla Brezilya ve Kolombiya için Model D'nin çıktıları esas alınacaktır.

Tablo 3. Ülkelere Ait Model ve F-Testi Sonuçları

\begin{tabular}{lllll}
\hline \hline & BRA & CHL & CHN & CLM \\
\cline { 2 - 5 } Model A (ADF) & -2.1671 & $-3.2673^{*}$ & -2.1333 & -2.4784 \\
$\tau_{D F}$ & & & & \\
Model B (FADF) & $-3.5688[2]$ & $-4.1526[2]^{* *}$ & $-2.6410[1]$ & $-4.3961[1]^{* *}$ \\
$\tau_{F D F}$ & $6.0545^{* *}$ & 4.2680 & 4.8515 & $7.3826^{*}$ \\
$F_{1}$ ist. (Model B vs. Model A) & & & & \\
Model C (ADF-SB) & & & & \\
$\tau_{D F S}$ & $-3.4898^{*}$ & $-4.4972^{* * *}$ & $-3.9227^{* *}$ & $-4.1476^{* *}$ \\
& $2005 / 03$ & $2000 / 05$ & $2002 / 02$ & $2006 / 06$ \\
$F_{2}$ ist. (Model C vs. Model A) & $5.0978^{* * *}$ & 0.25 & 0.32 & 0.49 \\
Model D (FADF-SB) & & & $5.9446^{* *}$ & $7.5423^{* * *}$ \\
$\tau_{F D F S}$ & $-5.1145[1]^{* * *}$ & $-5.3285[2]^{* * *}$ & $-4.7375[2]^{* *}$ & $-5.4675[1]^{* * *}$ \\
& $1998 / 12$ & $2001 / 02$ & $2014 / 07$ & $2014 / 07$ \\
$F_{3}$ ist. (Model D vs. Model A) & $6.2039^{* *}$ & 0.28 & 0.80 & 0.80 \\
$F_{4}$ ist. (Model D vs. Model B) & $6.1450^{* * *}$ & $6.0468^{* *}$ & $5.3432^{* *}$ & $6.4790^{* *}$ \\
$F_{5}$ ist. (Model D vs. Model C) & $12.3146^{* * *}$ & $9.6600^{* * *}$ & $8.6830^{*}$ & $5.3600^{* *}$ \\
\hline
\end{tabular}

Not: ${ }^{*}, * *$ ve ${ }^{* * *}$ sirasıyla $\% 10, \% 5$ ve \%1 düzeyinde anlamlılı̆̆ı, [ ] içerindeki değerler optimal frekans sayısı temsil etmektedir. Kritik değerler, Furuoka (2017)'nın çalışmasından elde edilmiştir.

Model D'ye göre Brezilya ve Kolombiya'da SGP geçerlidir. Şili ve Çin için F-testi sonuçları incelendiğinde Model A'nın Model B'ye, Model C'nin Model A'ya, Model D'nin Model A, B ve C'ye göre üstün olduğu görülmektedir. Şili ve Çin için de Model D sonuçları esastır ve buna göre SGP geçerlidir.

Tablo 4'te Çekya, Yunanistan, Macaristan ve Malezya'ya ait bulgular yer almaktadır. Çekya, Yunanistan ve Malezya için F-testi sonuçları incelendiğinde Model A'nın Model B'ye, Model C'nin Model A'ya, Model 
D'nin Model A, B ve C'ye göre üstün olduğu görülmektedir. Çekya, Yunanistan ve Malezya için Model D'nin sonuçları esastır ve buna göre SGP geçerlidir.

Tablo 4. Ülkelere Ait Model ve F-Testi Sonuçları

\begin{tabular}{|c|c|c|c|c|}
\hline & $\mathrm{CHZ}$ & GRC & HUN & MLY \\
\hline \multicolumn{5}{|l|}{ Model A (ADF) } \\
\hline$\tau_{D F}$ & -1.5810 & -1.8413 & -1.7663 & -2.5968 \\
\hline \multicolumn{5}{|l|}{ Model B (FADF) } \\
\hline$\tau_{F D F}$ & $-2.8625[1]$ & $-3.4258[1]$ & $-5.1800[1]^{* * *}$ & $-3.5754[1]$ \\
\hline$F_{1}$ ist. (Model B vs. Model A) & 3.7621 & 4.3368 & $12.7993^{* * *}$ & 3.2381 \\
\hline \multicolumn{5}{|l|}{ Model C (ADF-SB) } \\
\hline \multirow[t]{3}{*}{$\tau_{D F S}$} & $-3.7535^{* *}$ & $-3.6665^{*}$ & $-3.8776^{* *}$ & $-5.9562^{* * *}$ \\
\hline & $2012 / 03$ & $2002 / 11$ & $2001 / 04$ & 1997/07 \\
\hline & 0.71 & 0.35 & 0.28 & 0.14 \\
\hline$F_{2}$ ist. (Model C vs. Model A) & $6.7105^{* *}$ & $5.6746^{* *}$ & $6.5226^{* *}$ & $15.6562^{* * *}$ \\
\hline \multicolumn{5}{|l|}{ Model D (FADF-SB) } \\
\hline \multirow[t]{3}{*}{$\tau_{F D F S}$} & $-4.3064[1]^{*}$ & $-5.3206[2]^{* * *}$ & $-5.9466[1]^{* * *}$ & $-6.8765[2]^{* * *}$ \\
\hline & 2007/07 & $2002 / 04$ & $2008 / 07$ & 1997/07 \\
\hline & 0.53 & 0.32 & 0.57 & 0.14 \\
\hline$F_{3}$ ist. (Model D vs. Model A) & $5.0053^{*}$ & $7.6206^{* * *}$ & $11.8652^{* * *}$ & $10.8066^{* * *}$ \\
\hline$F_{4}$ ist. (Model D vs. Model B) & $6.1197^{* *}$ & $10.6252^{* * *}$ & $10.1479^{* * *}$ & $18.0068^{* * *}$ \\
\hline$F_{5}$ ist. (Model D vs. Model C) & $9.9348^{* * *}$ & $15.2044^{* * *}$ & $22.9435^{* * *}$ & $21.5018^{* * *}$ \\
\hline
\end{tabular}

Not: ${ }^{*},{ }^{* *}$ ve ${ }^{* * *}$ sırasıyla \%10, \%5 ve \%1 düzeyinde anlamlılı̆̆ı, [ ] içerindeki değerler optimal frekans sayısı temsil etmektedir. Kritik değerler, Furuoka (2017)'nın çalışmasından elde edilmiştir.

Macaristan için F-testi sonuçları incelendiğinde Model B ve C'nin Model A'ya, Model D'nin de Model A, B ve C'ye göre üstün olduğu görülmektedir. Macaristan için de Model D'nin sonuçları esastır ve SGP geçerlidir. 
Seçilmiş Gelişmekte Olan Ülkelerde Satın Alma Gücü Paritesinin Geçerliliğine İlişkin Ampirik Bir Çalışma
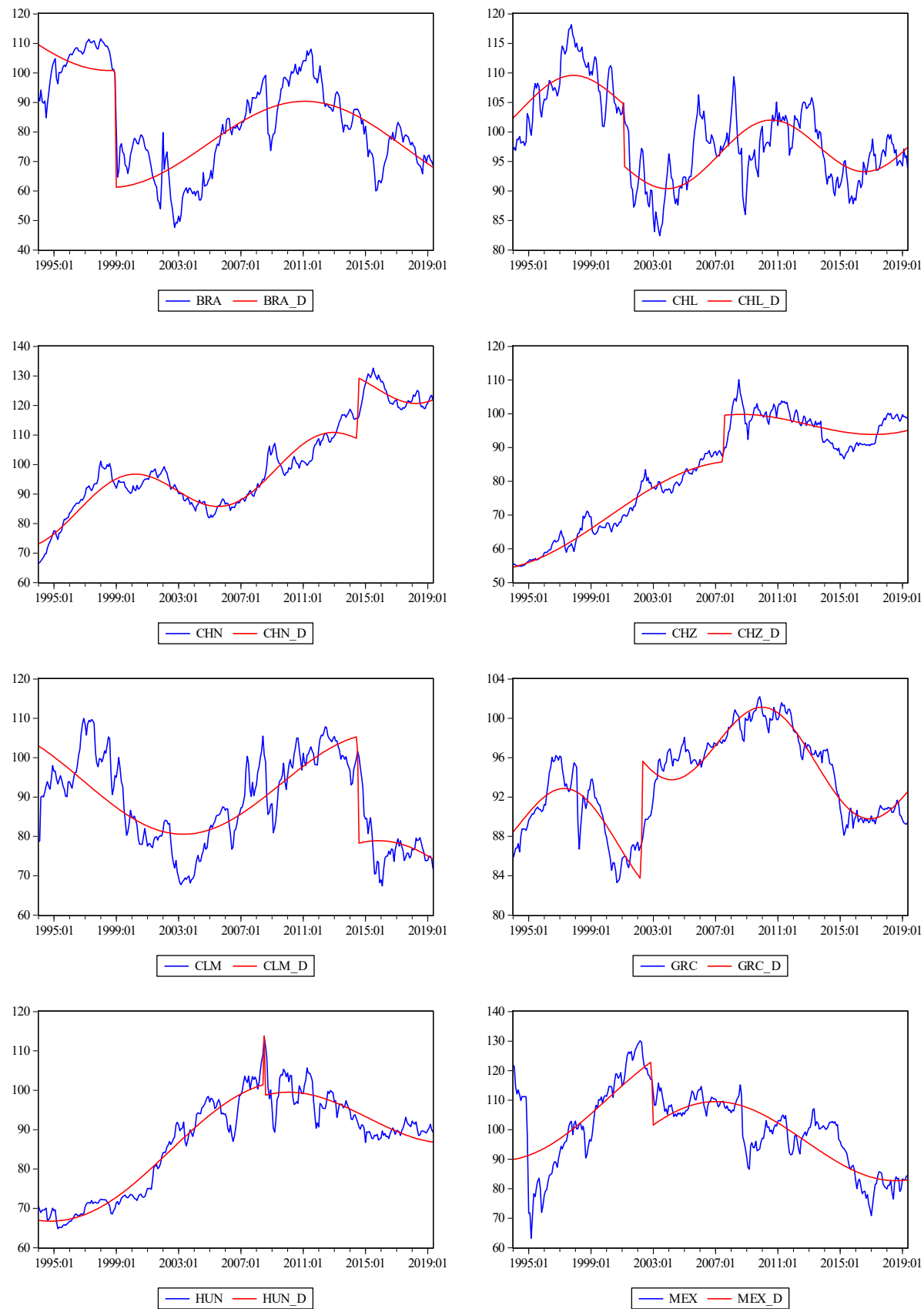

Şekil 1. Model D'ye Göre Ülkelerin Zamanyolu Grafiği 

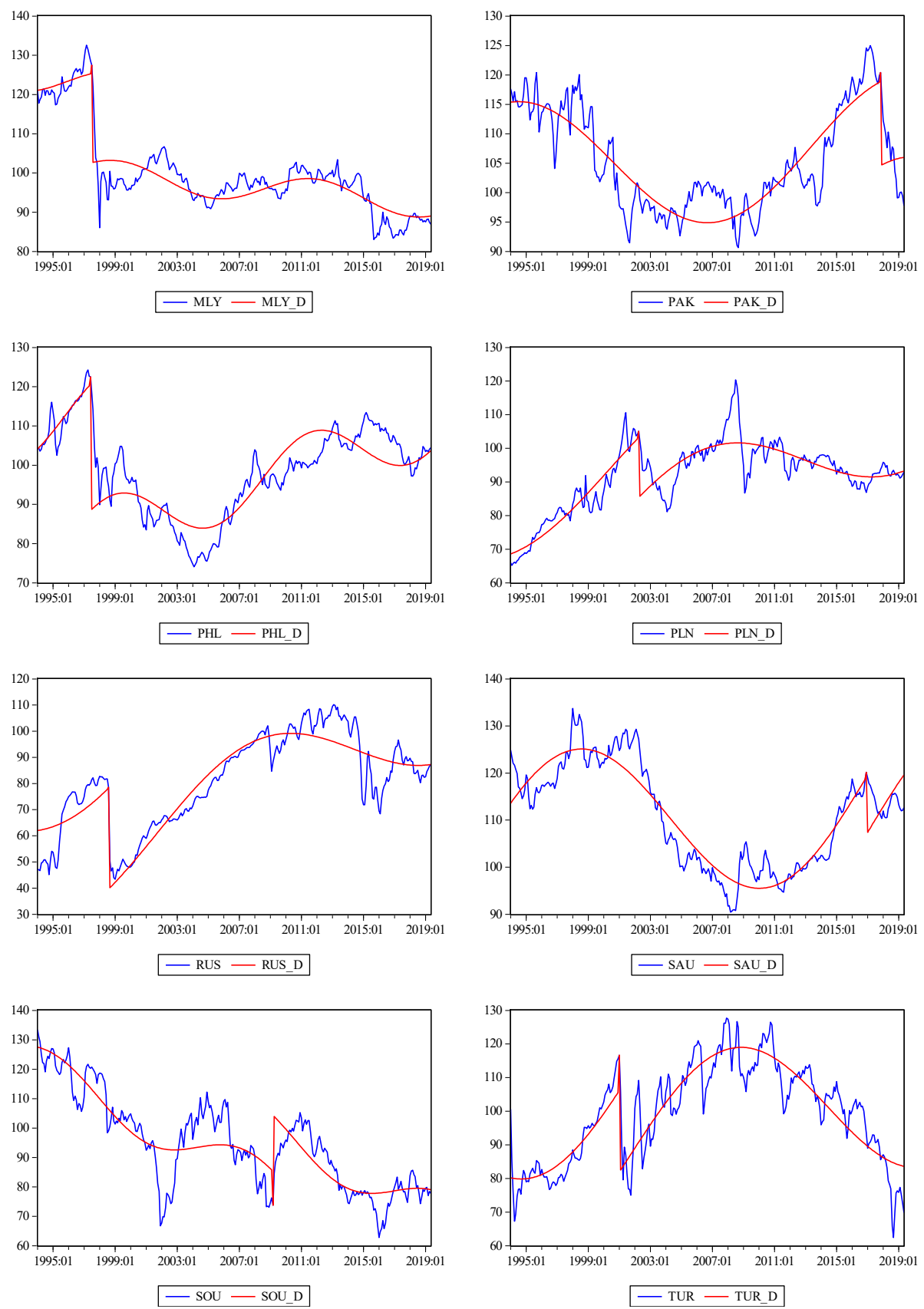

Şekil 2. Model D'ye Göre Ülkelerin Zamanyolu Grafiği 
Tablo 5. Ülkelere Ait Model ve F-Testi Sonuçlarn

\begin{tabular}{lllll}
\hline \hline & MEX & PAK & PHL & PLN \\
\cline { 2 - 3 } & -2.7882 & -2.3764 & -1.9952 & -2.9810 \\
$\tau_{D F}$ & & & & \\
Model B (FADF) & $-4.5236[1]^{* *}$ & $-3.4350[1]$ & $-4.3198[1]^{* *}$ & $-4.1325[1]^{*}$ \\
$\tau_{F D F}$ & $7.3240^{*}$ & 4.7381 & $8.3284^{*}$ & 4.1422 \\
$F_{1}$ ist. (Model B vs. Model A) & & & & \\
Model C (ADF-SB) & & $-3.8014^{* *}$ & $-4.5867^{* * *}$ & $-4.1473^{* *}$ \\
$\tau_{D F S}$ & $-5.1006^{* * *}$ & $1999 / 04$ & $1997 / 06$ & $2008 / 07$ \\
& $1998 / 01$ & 0.21 & 0.13 & 0.57 \\
$F_{2}$ ist. (Model C vs. Model A) & $10.3924^{* * *}$ & $4.4337^{*}$ & $10.3895^{* * *}$ & $7.7008^{* * *}$ \\
Model D (FADF-SB) & & & & \\
$\tau_{F D F S}$ & $-5.3892[1]^{* * *}$ & $-5.0905[1]^{* *}$ & $-5.9561[2]^{* * *}$ & $-5.8538[1]^{* * *}$ \\
& $2002 / 12$ & $2017 / 11$ & $1997 / 06$ & $2002 / 04$ \\
$F_{3}$ ist. (Model D vs. Model A) & $5.9165^{* *}$ & 0.94 & 0.13 & 0.32 \\
$F_{4}$ ist. (Model D vs. Model B) & $4.3451^{*}$ & $9.2313^{* * * *}$ & $9.9146^{* * *}$ & $6.7493^{* *}$ \\
$F_{5}$ ist. (Model D vs. Model C) & $11.7589^{* * *}$ & $13.5923^{* * *}$ & $17.7291^{* * *}$ & $13.4508^{* * *}$ \\
\hline \hline
\end{tabular}

Not: ${ }^{*}, * *$ ve ${ }^{* * *}$ sirasıyla $\% 10, \% 5$ ve \%1 düzeyinde anlamlilı̆̆ı, [ ] içerindeki değerler optimal frekans sayısı temsil etmektedir. Kritik değerler, Furuoka (2017)'nın çalışmasından elde edilmiştir.

Tablo 5'te Meksika, Pakistan, Filipinler ve Polonya'ya ait bulgular yer almaktadır. Meksika ve Filipinler için F-testi sonuçları incelendiğinde Model B ve C'nin Model A'ya, Model D'nin de Model A, B ve C'ye göre üstün olduğu görülmektedir. Her iki ülke için Model D'nin sonuçları esastır ve SGP geçerlidir. Pakistan ve Polonya için F-testi sonuçları incelendiğinde Model A'nın Model B'ye, Model C'nin Model A'ya, Model D’nin Model A, B ve C'ye göre üstün olduğu görülmektedir. Pakistan ve Polonya için de Model D'nin sonuçları esastır ve buna göre SGP geçerlidir.

Tablo 6'da Rusya, Suudi Arabistan, Güney Afrika ve Türkiye'ye ait bulgular yer almaktadır. Rusya ve Suudi Arabistan için F-testi sonuçları incelendiğinde Model A'nın Model B'ye, Model C'nin Model A'ya, Model D'nin Model A, B ve C'ye göre üstün olduğu görülmektedir. Rusya ve Suudi Arabistan için Model D'nin sonuçları esastır ve buna göre SGP geçerlidir. 
Tablo 6. Ülkelere Ait Model ve F-Testi Sonuçları

\begin{tabular}{|c|c|c|c|c|}
\hline & RUS & SAU & SOU & TUR \\
\hline \multicolumn{5}{|l|}{ Model A (ADF) } \\
\hline$\tau_{D F}$ & -2.8136 & -1.5828 & $-3.3566^{*}$ & -2.5672 \\
\hline \multicolumn{5}{|l|}{ Model B (FADF) } \\
\hline$\tau_{F D F}$ & $-4.1429[1]^{*}$ & $-3.3975[1]$ & $-3.7319[2]$ & $-5.7144[1]^{* * *}$ \\
\hline$F_{1}$ ist. (Model B vs. Model A) & 4.6453 & 5.4570 & 1.4785 & $13.0342^{* * *}$ \\
\hline \multicolumn{5}{|l|}{ Model C (ADF-SB) } \\
\hline \multirow[t]{3}{*}{$\tau_{D F S}$} & $-4.2876^{* *}$ & $-3.9536^{* *}$ & $-3.9537^{* *}$ & $-4.1054^{* *}$ \\
\hline & 2014/07 & $2002 / 10$ & $2009 / 03$ & 2016/09 \\
\hline & 0.81 & 0.34 & 0.60 & 0.89 \\
\hline$F_{2}$ ist. (Model C vs. Model A) & $5.4497^{* *}$ & $7.3915^{* * *}$ & 2.8821 & $5.4186^{* *}$ \\
\hline \multicolumn{5}{|l|}{ Model D (FADF-SB) } \\
\hline \multirow[t]{3}{*}{$\tau_{F D F S}$} & $-6.5619[1]^{* * *}$ & $-4.7962[1]^{* *}$ & $-4.9420[2]^{* * *}$ & $-7.9412[1]^{* * *}$ \\
\hline & 1998/08 & $2016 / 12$ & $2009 / 03$ & $2001 / 10$ \\
\hline & 0.18 & 0.91 & 0.60 & 0.27 \\
\hline$F_{3}$ ist. (Model D vs. Model A) & $9.7831^{* * *}$ & $6.5959^{* *}$ & $3.9028^{*}$ & $14.6491^{* * *}$ \\
\hline$F_{4}$ ist. (Model D vs. Model B) & $14.5014^{* * *}$ & $7.4977^{* * *}$ & $6.2749^{* *}$ & $15.0398^{* * *}$ \\
\hline$F_{5}$ ist. (Model D vs. Model C) & $19.5633^{* * *}$ & $13.0206^{* * *}$ & $7.3755^{* * *}$ & $28.4343^{* * *}$ \\
\hline
\end{tabular}

Not: ${ }^{*},{ }^{* *}$ ve ${ }^{* * *}$ strasıyla \%10, \%5 ve \%1 düzeyinde anlamlılı̆̆ı, [ ] içerindeki değerler optimal frekans sayısı temsil etmektedir. Kritik değerler, Furuoka (2017)'nın çalışmasından elde edilmiştir.

Türkiye için F-testi sonuçları incelendiğinde Model B ve C'nin Model A'ya, Model D'nin de Model A, B ve C'ye göre üstün olduğu görülmektedir. Türkiye için Model D'nin sonuçları esastır ve SGP geçerlidir. Güney Afrika için F-testi sonuçları incelendiğinde Model A'nın Model B ve C'ye, Model D’nin Model A, B ve C'ye göre üstün olduğu görülmektedir. Güney Afrika için de Model D'nin sonuçları esastır ve SGP geçerlidir.

Genel olarak sonuçlar özetlendiğinde, Brezilya, Kolombiya, Macaristan, Meksika, Filipinler ve Türkiye için doğrusal olmayan form ve yapısal değişimin hem ayrı ayrı hem de her ikisinin beraber ortaya çıktığı görülmüştür. Şili, Çin, Çekya, Yunanistan, Malezya, Pakistan, Polonya, Rusya ve Suudi Arabistan için doğrusal form kendi başına baskın gelmişken, yapısal değişimle beraber doğrusal olmayan form baskın gelmiştir. Diğer ülkelerden farklı olarak Güney Afrika için doğrusal olmayan form ve yapısal değişim ayrı ayrı kendi başına daha az baskın iken 
beraberce değerlendirildiğinde her ikisinin de geçerli olduğu görülmüştür. Böylelikle analize dahil edilen tüm ülkelerde doğrusal olmayan form ve yapısal değişimin geçerli olduğu görülmüş ve Furuoka (2017)' nin geliştirmiş olduğu Model D sonuçları esas alınmıştır. Model D sonuçlarına göre ise tüm ülkelerde SGP'nin geçerli olduğu görülmüştür.

\section{Sonuç}

İktisatçılar ve politika yapıcılar tarafından sıklıkla kullanılan SGP teorisi, döviz kurlarının yani farklı para birimlerinin birbiri cinsinden fiyatının belirlenmesinde kullanılan bir kavramdır. Bu çalışmada da gelişmekte olan ülkelerde SGP' nin geçerli olup olmadığı incelenmiştir. Bu amaç doğrultusunda, gelişmekte olan 16 ülkeye ait 1994.01-2019.05 dönemlerini kapsayan aylık reel efektif döviz kuru verileri kullanılarak birim kök testleri yapılmıştır. Birim kök testlerinin uygulanmasında serilerin doğrusallığ1 ve yapısal kırılma içerip içermediği önem kazanmaktadır. Furuoka (2017), serilerin doğrusallık ve yapısal kırılmalar altında dört farklı yöntemin mukayesesine olanak veren F-testini önermiştir. Bu çalışmada da literatürde yer alan diğer çalışmalardan farklı olarak dört yöntem uygulanmış ve F-testi sonuçlarına göre her ülke için en iyi model belirlenmiştir.

Çalışmanın sonucunda doğrusal olmayan ve yapısal değişimler altında Furuoka (2017) tarafından geliştirilen Fourier ADF (FADF-SB) testi sonuçları esas alınarak SGP teorisinin Türkiye'nin de aralarında bulunduğu gelişmekte olan 16 ülke için geçerliliğine ulaşılmıştır. SGP teorisinin geçerli olduğu durumlarda, döviz kurunun sabit olduğu kabul edilmektedir, döviz kurlarında meydana gelen değişimler SGP' den sapmalar olduğunu göstermektedir. Ayrıca, reel döviz kurlarının durağan seyretmesi, ülkelerin uygulamış olduğu finansal istikrar politikalarının kalitesini arttırması ve iktisadi anlamdaki rekabet düzeyini arttırabilmesi için döviz kurlarındaki istikrarı sağlaması gerekmektedir. 


\title{
EXTENDED ABSTRACT
}

\section{An Empirical Study on the Validity of Purchasing Power Parity in Selected Developing Countries}

\author{
Yusuf Bozgeyik - Ayşe Aydin \\ Gaziantep University
}

Purchasing power parity is a rate of change that eliminates global price diversity and equalizes purchasing power due to differences in currencies. The relationship between exchange rate and prices has led to controversy over purchasing power parity. According to this theory, it is aimed that the value of the national currency will be the same at home and abroad and the purchasing power between countries will be brought to the same level. Equalization of purchasing power across countries indicates that the nominal exchange rate will depend on relative price changes and as a result the real exchange rate will not change. From this perspective, purchasing power parity theory is used to determine the exchange rate, ie the price of different currencies in terms of each other.

While testing the validity of PPP (Purchasing Power Parity) theory, the stability of real exchange rates is being investigated. Changes in real exchange rates are indicative of deviations from the PPP. Non-stationary in these series shows that PPP theory is not valid.

The study aims to test the validity of the PPP hypothesis with unit root tests between 1994.01 and 2019.05 for 16 developing countries, including Turkey. In the first part of the study, the theory of PPP is mentioned in general terms. In the literature review section, studies that analyze the validity of PPP are included. In the third part, the methodology is introduced by mentioning the data set to be used in the study. In the last section, the validity of the PPP hypothesis will be analyzed and the results of the econometric application will be evaluated.

In the literature, there are studies that analyze the validity of PPP with unit root tests and cointegration tests. In our study, unlike literature, which included Turkey between the years 1994-2019, using monthly data from 16 developing countries the validity of PPP structures were analyzed with the unit root tests. 
In this study, monthly real effective exchange rate data of developing countries between 1994.01-2019.05 were used. Calculated with the help of real exchange rate formula. It represents real exchange rate, nominal exchange rate, overseas price level and domestic price level in the formula. In the selection of the sample, the classification of the developing countries created by Morgan Stanley Capital International (MSCI) was used and the countries whose data were not continuous during the analysis period were eliminated. Data of turkey TMB-EVDS and the data of the other developing countries IMF (International Monetary Fund) to the IFS (International Financial Statistics) was obtained from the database.

When the studies that test purchasing power parity are examined, it is seen that different findings are generally obtained and no consensus has been reached yet. The period covered by the data set used in the studies and especially the different econometric methods used cause this situation to occur. Studies in which the existence of PPP is examined by unit root tests generally show that ADF (Dickey and Fuller, 1979) unit root testing is used. Fourier ADF (FADF) test can be used when the series is not in linear form, and structural fracture ADF (ADF-SB) test can be used when the structural changes are examined. Furuoka (2017) developed the Fourier ADF (FADF-SB) test, which allows structural breaks if the series are not in linear form and contain structural change. He also proposed 5 different F-tests to determine the best model from within four alternative tests. He summarized the ADF test as Model A, the FADF test as Model B, the ADF-SB test as Model C and the FADF-SB test as Model D. If the series is in linear form and does not contain structural break Model A is preferred, If the series is in nonlinear form and does not contain structural break, Model B will be preferred if it contains linear form and structural break, Model $\mathrm{C}$ will be preferred if it contains nonlinear form and structural break, Model D will be preferred. These F-tests will determine the most appropriate model for the data set and the outputs of that model will be based on.

The study concluded that PPP theory was valid for 16 developing countries, including Turkey, based on Fourier ADF (FADF-SB) test results developed by Furuoka (2017) under nonlinear and structural changes. Where the PPP theory is valid, the exchange rate is assumed to be cons- 
tant, changes in exchange rates indicate deviations from the PPP. In addition, real exchange rates should remain stable, improve the quality of financial stability policies implemented by countries and increase stability in order to increase economic competitiveness.

\section{Kaynakça / References}

Alba, J. ve Park, D. (2005). An empirical investigation of purchasing power parity (PPP) for Turkey. Journal of Policy Modelling, 27, 989-1000.

Alper, A. (2015). Testing the validity of purchasing power parity for BRICS countries using nonlinear unit root test. Akademik Araştırmalar ve Çalışmalar Dergisi, 7(12), 92-101.

Aslan, N. ve Kanbur, N. (2007). Türkiye'de 1980 sonrası satın alma gücü paritesi yaklaşımı. Marmara Üniversitesi İ.I.B.F. Dergisi, 23(2), 9-43.

Bahmani-Oskooee, M. ve Rhee, H.-J. (1992). Testing for long run purchasing power parity: an examination of Korean won. International Economic Journal, 6(3), 93-103.

Benassy, A. D. (2005). Real equilibrium exchange rates: A G20 panel cointegration approach. Thema working paper .

Ceviş, İ. ve Ceylan, R. (2015). Kırılgan beşlide satın alma gücü paritesi (SAGP) hipotezinin test edilmesi. Journal of Yasar University, 10(37), 6381-6477.

Cuestas, J. ve Regis, P. (2013). Purchasing power parity in OECD countries: Nonlinear unit root tests revisited. Economic Modelling, 32, 343-346.

Çağlayan, E. ve Şak, N. (2009). OECD ülkelerinde satınalma gücü paritesi: Panel eşbütünleşme yaklaşımı. Marmara Üniversitesi İ.I.B.F. Dergisi, 26(1), 483-500.

Çil, N. ve Yıldırım Tıraşoğlu, B. (2018). Validity of purchasing power parity in fragile five countries: The bayesyen unit root analysis. Social Sciences Research Journal, 7(2), 82-90.

Destek, M. A. ve Okumuş, İ. (2016). Satın alma gücü paritesi hipotezi geçerliliğinin fourier birim kök testleri ile incelenmesi: OECD ülkeleri örneği. Gaziantep University Journal of Social Sciences , 73-87.

Dickey, D. A. ve Fuller, W. A. (1979). Distribution of the estimators for autoregressive time series with a unit root. Journal of the American statistical association, 74(366a), 427-431.

Enders, W. ve Lee, J. (2012). The flexible Fourier form and Dickey-Fuller type unit root tests. Economics Letters, 117(1), 196-199. 
Erlat, H. (2003). The nature of persistence in Turkish real exchange rates. Emerging Markets Finance\& Trade, 39(2), 70-97.

Furuoka, F. (2017). A new approach to testing unemployment hysteresis. Empirical Economics, 53(3), 1253-1280. doi:10.1007/s00181-016-1164-7

Gemici, E. ve Polat, M. (2018). MIST Borsalarında rassal yürüyüş hipotezi. Eskişehir Osmangazi Üniversitesi İktisadi ve İdari Bilimler Dergisi, 13(1), 129-142. doi:10.17153/oguiibf.344882

Guloglu, B. I. (2011). Testing the validity of quasi PPP hypothesis: Evidence from a recent panel unit root test with structural breaks. Applied economics letters, 18(18), 1817-1822.

Gürbüz, H. ve Hasgür, İ. (1997). Satın alma gücü paritesi örneğinin mevsimsel verilere analizi üzerine bir uygulama: Eşbütünleşme. SDÜ İktisadi ve İdari Bilimler Fakültesi Dergisi, 2(2), 171-196.

Perron, P. ve Vogelsang, T. J. (1992). Nonstationarity and level shifts with an application to purchasing power parity. Journal of Business \& Economic Statistics, 10(3), 301-320. doi:10.1080/07350015.1992. 10509907

Sağlam, Y. (2017). Satın alma gücü paritesi hipotezi'nin panel çoklu yapısal kırılma testleri ile analizi: BRICT örneği. LAÜ Sosyal Bilimler Dergisi, 8(1), 19-34.

Şener, S., Yılanc1, V. ve Canpolat, E. (2015). Satın alma gücü paritesi ve varyaslarının Türkiye için sınanması. Uluslararası Yönetim İktisat ve İşletme Dergisi, 11(25), 53-63.

Tatoğlu, F. (2009). Reel efektif döviz kurunun durağanlığının yapısal kırılmalı panel birim kök testleri kullanılarak sınanması. Doğuş Üniversitesi Dergisi, 10(2), 310-323.

Tıraşoğlu, B. Y. (2014). Yapısal kırılmalı birim kök testleri ile OECD ülkelerinde satın alma gücü paritesi geçerliliğinin testi. Ekonometri ve İstatistik Dergisi , 0(20), 68-87.

Yıldırım, K., Mercan, M. ve Kostakoğlu, F. (2013). Satın alma gücü paritesinin geçerliliğinin test edilmesi: Zaman serisi ve panel veri analizi. Eskişehir Osmangazi Üniversitesi İIBF Dergisi, 8(3), 75-95.

Yıldırım, S. ve Yıldırım, Z. (2012). Reel efektif döviz kuru üzerine kırılmalı birim kök testleri ile Türkiye için satın alma gücü paritesi hipotezinin geçerliliğinin sınanması. Marmara Üniversitesi I.I.̇.B. Dergisi, 33(2), 221238. 
Zivot, E. ve Andrews, D. W. K. (1992). Further evidence on the great crash, the oil-price shock, and the unit-root hypothesis. Journal of Business \& Economic Statistics, 10(3), 251-270. doi:10.1080/07350015.1992. 10509904

\section{Kaynakça Bilgisi / Citation Information}

Bozgeyik, Y. ve Aydın, A. (2019). Seçilmiş gelişmekte olan ülkelerde satın alma gücü paritesinin geçerliliğine ilişkin ampirik bir çalışma. OPUS-Uluslararası Toplum Araştırmaları Dergisi, 13(19), 2068-2089. DOI: 10.26466/opus.596875 